\title{
Size and Gender Matching in Heart Transplantation - Optimizing Donor Utilization in an Era of Changing Donor and Recipient Characteristics
}

\author{
William Ziaziaris • Hong Chee Chew • Kumud Dhital • \\ Christopher Hayward • Henry Pleass • Peter Macdonald
}

Published online: 6 September 2014

(C) Springer International Publishing AG 2014

\begin{abstract}
Heart transplantation is limited by donor organ availability. Increased use of marginal donor organs, combined with increased recipient complexity, has increased the risk of primary graft failure. These changes in donor and recipient characteristics have led to a renewed focus on modifiable donor-recipient characteristics that have historically been shown to impact on post-transplant outcomes, namely size and gender matching. Recently published analyses of large registries have found that the use of body weight to size donor organs for transplantation fails to predict post-transplant outcomes, whereas newer methods such as predicted heart mass (utilizing height, age, and gender as well as weight)
\end{abstract}

\author{
W. Ziaziaris $\cdot$ H. Pleass \\ University of Sydney Department of Surgery, Westmead Hospital, \\ Cnr Hawkesbury Rd \& Darcy Rd, Westmead, NSW 2145, Australia \\ W. Ziaziaris \\ e-mail: wzia5232@uni.sydney.edu.au \\ H. Pleass \\ e-mail: henry.pleass@health.nsw.gov.au \\ H. C. Chew $\cdot$ K. Dhital $\cdot$ C. Hayward · P. Macdonald \\ Victor Chang Cardiac Research Institute, Liverpool St, Darlinghurst, \\ NSW 2010, Australia \\ H. C. Chew \\ e-mail: H.Chew@victorchang.edu.au \\ K. Dhital \\ e-mail:kdhital@stvincents.com.au \\ C. Hayward \\ e-mail: cshayward@stvincents.com.au \\ H. C. Chew $\cdot$ K. Dhital $\cdot$ C. Hayward $\cdot$ P. Macdonald $(\bowtie)$ \\ Heart \& Lung Transplant Unit, St Vincent's Hospital, Victoria St, \\ Darlinghurst, NSW 2010, Australia \\ e-mail: pmacdonald@stvincents.com.au \\ H. C. Chew $\cdot$ K. Dhital $\cdot$ C. Hayward $\cdot$ P. Macdonald \\ University of New South Wales Department of Medicine, St \\ Vincent's Hospital, Victoria St, Darlinghurst, NSW 2010, Australia

correlate well with a number of post-transplant outcomes, including survival. The well recognized risks of under-sizing in female donor:male recipient transplants and in recipients with increased pulmonary vascular resistance are reinforced by recent studies. Over-sizing is not associated with increased risk or survival benefit versus ideally matched adult donor hearts.

Keywords Donor recipient size matching - Donor recipient gender matching $\cdot$ Heart transplantation $\cdot$ Primary graft failure

\section{Introduction}

Heart transplantation is the most effective treatment for endstage heart disease; however, it carries a substantial operative mortality risk of between 5 and $10 \%$ related mainly to primary allograft failure [1]. Multiple donor, recipient, and procedural factors have been implicated in the pathogenesis of primary graft failure $[2 \cdot]$. Few of these risk factors are modifiable, but donor recipient size and gender matching are two risk factors that are. The major goal of donor-recipient matching is to avoid size discrepancies that adversely affect cardiac function and place the recipient at risk of primary graft failure. Current guidelines from the International Society of Heart and Lung Transplantation recommend the use of adult heart donors to within $30 \%$ of recipient body weight, and further limit female to male donations to within $20 \%$ [3•]. The guidelines state that a male donor of average weight $(70 \mathrm{~kg})$ can be safely used for any recipient regardless of weight [3•]; however, these recommendations are based on studies published more than 20 years ago [4-7]. Since then, there have been substantial changes in the characteristics of both donors and recipients, driven in part by the paucity of suitable donor organs relative to need and in part by the dramatic evolution of mechanical circulatory support for patients with end-stage 
heart failure. In light of these changes, we undertook a review of recent publications examining the impact of donor-recipient size and gender matching on post-transplant outcomes. The aim of this review was first to determine whether recent publications support the current recommendations regarding donor-recipient matching and, second, whether there may be alternative methods of donor-recipient matching that more accurately predict post-transplant outcomes.

\section{Changing Characteristics of Donors and Recipients}

The chronic shortage of standard criteria donor hearts has resulted in increased utilization of hearts from so called 'marginal' or 'extended criteria' donors [8]. These include hearts from older donors, and hearts with myocardial dysfunction, left ventricular hypertrophy, extended ischemic times, conduction abnormalities, or a combination of these [8-12]. While use of these donors has helped to maintain or increase heart transplant activity, their use is associated with an increased risk of primary graft failure and post-transplant mortality [2•]. As a consequence, there is considerable variability between individual transplant centers regarding acceptance of marginal donors [13], and also uncertainty as to whether the same donor-recipient size-matching and gender-matching criteria should be applied to these donors as for standard criteria donors.

The success of heart transplantation as a therapy for endstage heart failure has resulted in a progressive broadening of recipient acceptance criteria, with the result that the potential pool of heart transplant recipients is dramatically larger now than it was 20 years ago. The changing characteristics of heart transplant recipients were highlighted in the latest report of the International Society for Heart and Lung Transplantation, which noted increasing age and co-morbidities of heart transplant recipients in the most recent era [8]. As with changing donor characteristics, changing recipient characteristics, such as advanced age and diabetes mellitus, are associated with an increased risk of primary graft failure [2•, 14•]. In addition, broadening acceptance criteria has increased the number of people waiting for heart transplantation. In the absence of a corresponding increase in donor organ availability, this has led to an increased reliance on acute and/or chronic mechanical circulatory support to bridge patients to heart transplantation $[1,8]$. Recent publications from large observational registries demonstrate an increased risk of primary graft failure and mortality after transplantation in patients supported with extra-corporeal mechanical assist devices $[15,16]$. However, post-transplant outcomes with long-term intra-corporeal pulsatile or continuous flow left ventricular assist devices (VADs) are more favorable, with post-transplant outcomes comparable to those of non-VAD patients $[17,18]$. Nonetheless, mechanical circulatory support prior to heart transplantation is associated with increased cardiopulmonary bypass time, bleeding, and transfusion requirements at the time of transplantation [19]. These events may trigger both an acute pulmonary hypertensive reaction and a systemic inflammatory response syndrome with resultant vasoplegia [19], circumstances in which an undersized or otherwise marginal donor heart is likely to fail.

\section{The Validity of Using Body Weight as a Means of Sizing Hearts}

Currently, the most widely utilized measure to match cardiac donors to recipients is body weight ratio; however, the validity of using body weight to estimate heart size and as a basis for matching donors and recipients has been challenged recently by the findings of a number of large retrospective heart transplant registry studies $[20,21 \bullet \cdot, 22 \bullet \bullet, 23 \bullet \bullet, 24]$. The details and major findings of these studies are summarized in Table 1.

\section{Post-Transplant Outcomes with Undersized Hearts}

Although Smits et al. [25] reported that a donor-recipient weight ratio $<0.8$ was associated with inferior posttransplant survival in the Eurotransplant Heart Transplant Registry, this was not found to be the case in a larger United Network for Organ Sharing (UNOS) Registry study reported by Patel et al. [22••]. In the UNOS Registry Study, donor-recipient weight ratio $<0.8$ was not a significant predictor of mortality post-heart transplantation, with the exception that recipients with high pulmonary vascular resistance (PVR) who received an undersized heart had poorer survival. In addition, males with elevated PVR receiving hearts from female donors had significantly worse survival than males who received hearts from male donors [22••]. In a subsequent UNOS Registry study, Jayarajan et al. [20] reported that donor-recipient weight ratios down to $<0.6$ were not associated with any increase in mortality in male-to-male, female-to-female, and male-to-female heart transplants; however, donor recipient weight ratios $<0.9$ were associated with increased mortality in female-to-male transplants [20]. In the most recent and largest analysis of the UNOS Registry published to date, Reed et al. [23・•] analyzed post-transplant survival in 31,634 heart transplant recipients stratified by donor-recipient weight ratio. A total of $86 \%$ of donors were within $30 \%$ of the recipient weight, reflecting current guidelines. When stratified into septiles from the most undersized to the most oversized weight-matches, they observed no difference in post-transplant survival across the seven categories. 


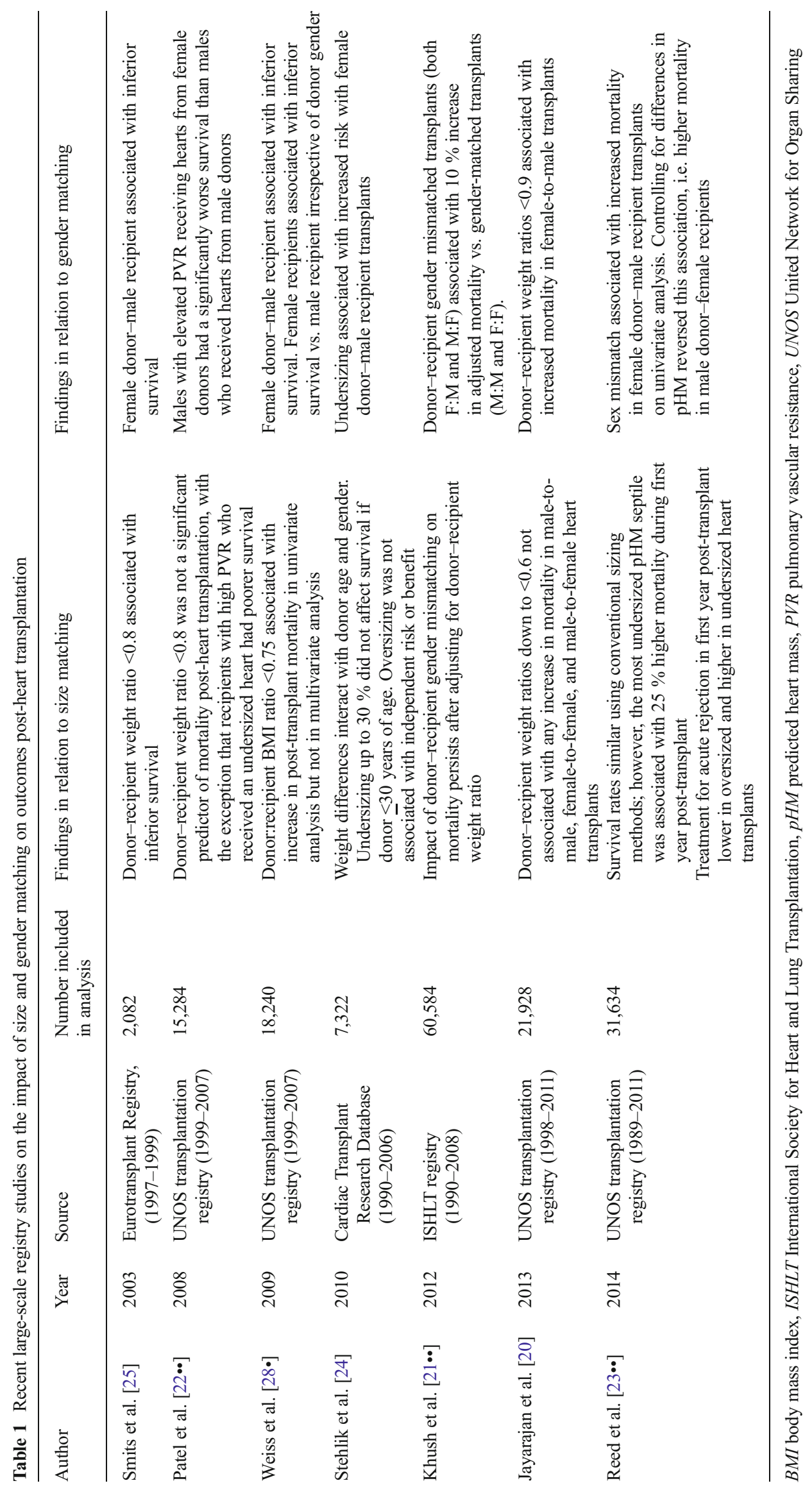




\section{Post-Transplant Outcomes with Oversized Hearts}

Recent large UNOS Registry analyses have also compared the post-transplant outcomes of transplants performed with oversized hearts compared with size-matched hearts [22••, 23••]. Both analyses found no survival benefit or risk in adult heart transplants performed with oversized hearts compared with optimally sized hearts, including in recipients with elevated PVR. In the most recent UNOS report, male recipients of oversized female hearts were uncommon, representing $<1 \%$ of the study cohort, whereas the majority of male-to-female transplants were oversized [23••]. Interestingly, Reed et al. [23••] observed that treatment for rejection during the first year post-transplant was significantly reduced in oversized heart transplants and increased in undersized hearts compared with ideally sized matched heart transplants.

Oversized cardiac allografts are often implanted in small children and infants for whom optimally sized donors are scarce [26]. Recipients of oversized allografts are at risk of 'big heart or hyperperfusion syndrome', which usually manifests as an acute neurological syndrome with headache, drowsiness, and occasionally fitting in the immediate posttransplant period [27]. Otherwise, post-transplant morbidity and long-term post-transplant survival appear to be similar in pediatric recipients of oversized compared with optimally sized hearts [26].

\section{The Interaction Between Size Matching and Gender Matching}

Multiple observational registry studies have highlighted the increased mortality risk associated with the transplantation of an undersized female donor heart into a male recipient, particularly in the context of recipient pulmonary hypertension $[20,22 \bullet \bullet, 24,25]$. The first large multicenter registry study to specifically examine the impact of donor and recipient gender on post-transplant outcomes was that of Weiss et al. [28•]. These authors undertook a retrospective review of 18,240 heart transplant recipients in the UNOS Registry. They confirmed the adverse outcomes associated with transplantation of female donors into male recipients. They also reported that female recipients experienced an increased mortality relative to male recipients. There was a trend towards increased mortality in male donor to female recipient (M:F) transplants compared with female donor to female recipient transplants (F:F), but this was non-significant [28•]. The largest study to examine the impact of donor-recipient gender mismatching on post-transplant outcomes was that conducted by Khush et al. [21••]. These authors undertook a retrospective review of 60,584 heart transplant recipients enrolled in the International Society for Heart and Lung Transplantation
Registry. They reported that donor-recipient gender mismatched transplants (both F:M and M:F) were associated with a statistically significant $10 \%$ increase in adjusted mortality compared with gender-matched transplants (M:M and $\mathrm{F}: \mathrm{F}$ ). These differences persisted after adjusting for donor-recipient weight ratio, which led the authors to conclude that the findings were related to gender differences rather than size differences; however, inspection of the survival curves suggests different mechanisms of death depending on the type of gender mismatch. Whereas the excess mortality in F:M transplants was evident in the immediate post-transplant period consistent with death due to primary graft failure, the excess mortality in M:F transplants only developed years after transplantation, suggesting an alternative explanation for the increased mortality. Similar differences in post-transplant mortality trends between F:M and M:F transplants were reported in the study by Weiss et al. [28•].

Reed et al. [23••] also examined the interaction between donor size mismatch and gender mismatch. Consistent with previous reports, they found that, in unadjusted analyses, F:M transplants (but not M:F) were associated with a significant increase in early post-transplant mortality. After adjusting for multiple co-variates, including predicted heart mass, they observed the opposite trends - no difference in survival in F:M transplants but an increased mortality in M:F transplants. The authors concluded that survival differences in F:M heart transplants were altered by and largely attributable to differences in predicted heart mass. Conversely, the excess mortality in M:F recipients could not be explained by size differences but rather pointed to a different cause of death such as increased rate of rejection $[29,30]$ or coronary allograft vasculopathy $[31,32]$.

\section{The Interaction Between Size Matching and Other Risk Factors for Primary Graft Failure}

Several studies have highlighted the existence of multiple independent risk factors that contribute to primary graft failure and how these risk factors may interact to magnify the risk [2•, 14•, 33]. In another large retrospective UNOS Registry analysis, Russo et al. [34] reported an adverse interaction between increasing donor age and increasing ischemic time. In that study, there was no detectable adverse effect of ischemic time on survival after heart transplantation when the donor was less than 20 years of age. In contrast, when the donor age increased above 20 years, a prolonged ischemic time had a significant negative impact on survival. This effect became even more marked when the donor age exceeded 35 years. More recently, Segovia et al. [14•] developed a risk prediction score for primary graft failure based on the presence of six independent risk factors, including donor age, 
ischaemic time, and recipient age [14•]. In another study of patients enrolled in the Cardiac Transplant Research Database, Stehlik et al. [24] reported that donor-recipient weight differences interacted with age and gender. In that study, weight differences of up to $30 \%$ did not affect survival so long as the donor was aged 30 years or younger. Donor and recipient gender further modified the degree of risk: risk was higher in female donors and when recipients were male. Considered together, these studies suggest that optimal donor-recipient size matching is particularly important when other risk factors for primary graft failure (such as increased donor age, older recipient age, or prolonged ischemic time) are also present.

\section{Alternative Approaches to Donor-Recipient Size Matching}

A number of authors have suggested that alternative approaches to donor-recipient size matching [23••, 35, 36] may be more predictive of post-transplant outcome and have postulated that alternative approaches to donor-recipient matching could potentially expand opportunities for transplantation that may otherwise be overlooked due to concern about undersizing $[21 \bullet \bullet, 22 \bullet \bullet, 23 \bullet \bullet]$. Reed et al. [23••] calculated predicted heart mass using formulae derived from studies using cardiac magnetic resonance imaging (MRI) in normal adults and that incorporate height, weight, age, and sex $[23 \bullet \bullet, 37,38]$. Using this model of predicted heart mass (pHM), size mismatch was found to be a powerful independent predictor of survival, with recipients of the most undersized hearts (donor $\mathrm{pHM}$ $>10-15 \%$ below recipient $\mathrm{pHM}$ ) having a $25 \%$ increase in mortality and a $33 \%$ increase in acute rejection at 1 year compared with ideally matched donor recipient pairs. Strikingly, the increase in mortality in the most undersized hearts was greatest in the first 30 days, with a $36 \%$ increase in relative risk of death during this period. Although cause of death was not specifically analyzed in the study, this finding suggests that an increased rate of primary graft failure in the most undersized cohort was the most likely explanation. As suggested by the authors, adoption of donor-recipient pHM ratio to match donors and recipients is unlikely to increase the number of heart transplants performed, but it is likely to lead to greater utility by a redistribution of donor hearts to recipients who are at lower risk of primary graft failure. Another potential benefit is an expanded opportunity for female recipients through better recognition of acceptable size matching with small male donors who could otherwise be overlooked due to concerns of undersizing based on body weight differences [23••].
Some authors have also suggested the use of simply obtained echocardiographic measurements to assess total cardiac volume. This may be particularly valuable in pediatric heart transplantation where use of markedly oversized donors may necessitate delayed chest closure to prevent hemodynamic compromise of the newly transplanted heart. Camarda et al. [35] reported that left ventricular end-diastolic volume measured by a modified Simpson's rule from a four-chamber view of the heart correlated extremely well with MRI-determined total cardiac volume. Zuckerman et al. [36] demonstrated a highly significant linear correlation between body height and a novel measurement from the superior vena cava-right atrium junction to inferior vena cava-right atrium junction and suggested that use of these parameters would provide better donor recipient size matching than the use of body weight. As yet, no studies have examined post-transplant outcomes using these echocardiographic measurements, and it remains to be seen whether either method provides a more accurate prediction of post-transplant outcomes compared with matching based on body weight.

\section{Future Trends and Conclusions}

Matching potential heart donors with suitable recipients is a complex process that requires consideration of issues of utility, equity, and logistics. The changing characteristics of both donors and recipients, combined with an increased risk of primary graft failure, have led to a renewed focus on donor heart preservation and donor-recipient matching. Novel approaches to donor organ preservation and retrieval such as ex vivo machine perfusion of donor hearts are exciting developments; however, it remains to be seen whether these approaches lower the risk of primary graft failure and improve post-transplant outcomes. Regardless of developments in donor heart preservation, optimal donor-recipient size matching will remain an essential step in ensuring the success of heart transplantation. Traditional methods of size matching for heart transplantation based on donor and recipient body weight have been found to be poorly predictive of post-transplant outcomes in the current era. Newer methods of donorrecipient size matching that take into account age, gender, and height in addition to weight appear to be more reliable in predicting heart transplant outcomes and, if adopted, should enhance the safety of this life-saving procedure.

\section{Compliance with Ethics Guidelines}

Conflict of Interest W Ziaziaris, HC Chew, K Dhital, C Hayward, H Pleass, and P Macdonald all declare no conflicts of interest. 
Human and Animal Rights and Informed Consent This article does not contain any studies with human or animal subjects performed by any of the authors.

\section{References}

Papers of particular interest, published recently, have been highlighted as:

- Of importance

•- Of major importance

1. Stehlik J, Edwards LB, Kucheryavaya AY, Benden C, Christie JD, Dipchand AI, et al. The Registry of the International Society for Heart and Lung Transplantation: 29th official adult heart transplant report-2012. J Heart Lung Transplant. 2012;31(10):1052-64.

2. Iyer A, Kumarasinghe G, Hicks M, Watson A, Gao L, Doyle A, et al. Primary graft failure after heart transplantation. J Transplant. 2011;2011:175768. Recent comprehensive review of primary graft failure after heart transplantation.

3. Costanzo MR, Dipchand A, Starling R, Anderson A, Chan M, Desai S, et al. The International Society of Heart and Lung Transplantation Guidelines for the care of heart transplant recipients. J Heart Lung Transplant. 2010;29(8):914-56. Current International Society of Heart and Lung Transplantation guidelines for peri-operative management of heart transplant recipients.

4. Blackbourne LH, Tribble CG, Langenburg SE, Sinclair KN, Rucker GB, Chan BB, et al. Successful use of undersized donors for orthotopic heart transplantation-with a caveat. Ann Thorac Surg. 1994;57(6):1472-5. discussion 5-6.

5. Chan BB, Fleischer KJ, Bergin JD, Peyton VC, Flanagan TL, Kern $\mathrm{JA}$, et al. Weight is not an accurate criterion for adult cardiac transplant size matching. Ann Thorac Surg. 1991;52(6):1230-5. discussion 5-6.

6. Sethi G, Lanauze P, Rosado L, Huston C, McCarthy M, Butman S, et al. Clinical significance of weight difference between donor and recipient in heart transplantation. J Thorac Cardiovasc Surg. 1993;106(3):444-8.

7. Young JB, Naftel DC, Bourge RC, Kirklin JK, Clemson BS, Porter $\mathrm{CB}$, et al. Matching the heart donor and heart transplant recipient. Clues for successful expansion of the donor pool: a multivariable, multiinstitutional report. The Cardiac Transplant Research Database Group. J Heart Lung Transplant. 1994;13(3):353-64. discussion 64-5.

8. Lund LH, Edwards LB, Kucheryavaya AY, Dipchand AI, Benden $\mathrm{C}$, Christie JD, et al. The registry of the International Society for Heart and Lung Transplantation: thirtieth official adult heart transplant report - 2013; focus theme: age. J Heart Lung Transplant. 2013;32(10):951-64.

9. Jeevanandam V, Furukawa S, Prendergast TW, Todd BA, Eisen HJ, McClurken JB. Standard criteria for an acceptable donor heart are restricting heart transplantation. Ann Thorac Surg. 1996;62(5): $1268-75$

10. Drinkwater DC, Laks H, Blitz A, Kobashigawa J, Sabad A, Moriguchi J, et al. Outcomes of patients undergoing transplantation with older donor hearts. J Heart Lung Transplant. 1996;15(7):684 91.

11. Blanche C, Kamlot A, Blanche DA, Kearney B, Magliato KE, Czer LS, et al. Heart transplantation with donors fifty years of age and older. J Thorac Cardiovasc Surg. 2002;123(4):810-5.
12. Mitropoulos FA, Odim J, Marelli D, Karandikar K, Gjertson D, Ardehali A, et al. Outcome of hearts with cold ischemic time greater than 300 minutes. A case-matched study. Eur J Cardiothorac Surg. 2005;28(1):143-8.

13. Khush KK, Menza R, Nguyen J, Zaroff JG, Goldstein BA. Donor predictors of allograft use and recipient outcomes after heart transplantation. Circ Heart Fail. 2013;6(2):300-9.

14. Segovia J, Cosio MD, Barcelo JM, Bueno MG, Pavia PG, Burgos $\mathrm{R}$, et al. RADIAL: a novel primary graft failure risk score in heart transplantation. J Heart Lung Transplant. 2011;30(6):644-51. Recently developed clinical risk score for estimating risk of primary graft failure based on donor, recipient, and procedural characteristics.

15. Russo MJ, Hong KN, Davies RR, Chen JM, Sorabella RA, Ascheim DD, et al. Posttransplant survival is not diminished in heart transplant recipients bridged with implantable left ventricular assist devices. J Thorac Cardiovasc Surg. 2009;138(6):1425-32. e1-3.

16. Patlolla V, Patten RD, Denofrio D, Konstam MA, Krishnamani R. The effect of ventricular assist devices on post-transplant mortality an analysis of the United network for organ sharing thoracic registry. J Am Coll Cardiol. 2009;53(3):264-71.

17. Nativi JN, Drakos SG, Kucheryavaya AY, Edwards LB, Selzman $\mathrm{CH}$, Taylor DO, et al. Changing outcomes in patients bridged to heart transplantation with continuous- versus pulsatile-flow ventricular assist devices: an analysis of the registry of the International Society for Heart and Lung Transplantation. J Heart Lung Transplant. 2011;30(8):854-61.

18. Ventura PA, Alharethi R, Budge D, Reid BB, Horne BD, Mason NO, et al. Differential impact on post-transplant outcomes between pulsatile- and continuous-flow left ventricular assist devices. Clin Transplant. 2011;25(4):E390-5.

19. Patarroyo M, Simbaqueba C, Shrestha K, Starling RC, Smedira N, Tang WH, et al. Pre-operative risk factors and clinical outcomes associated with vasoplegia in recipients of orthotopic heart transplantation in the contemporary era. J Heart Lung Transplant. 2012;31(3):282-7.

20. Jayarajan SN, Taghavi S, Komaroff E, Mangi AA. Impact of low donor to recipient weight ratios on cardiac transplantation. J Thorac Cardiovasc Surg. 2013;146(6):1538-43.

21.• Khush KK, Kubo JT, Desai M. Influence of donor and recipient sex mismatch on heart transplant outcomes: analysis of the International Society for Heart and Lung Transplantation Registry. J Heart Lung Transplant. 2012;31(5):459-66. Recent analysis of largest heart transplant registry to assess the impact of donor:recipient gender matching on survival after heart transplantation.

22.• Patel ND, Weiss ES, Nwakanma LU, Russell SD, Baumgartner WA, Shah AS, et al. Impact of donor-to-recipient weight ratio on survival after heart transplantation analysis of the United Network for Organ Sharing database. Circulation. 2008;118(14 Suppl 1): S83-8. First of a series of UNOS registry analyses examining the impact of donor:recipient size mismatching and post-transplant survival.

23.• Reed RM, Netzer G, Hunisicker L, Mitchell BD, Rajagopal K, Scharf S, et al. Cardiac size and sex-matching in heart transplantation. JACC Heart Fail. 2014;2(1):73-83. Latest and largest in a series of UNOS registry analyses examining the impact of donor: recipient size mismatching and post-transplant survival. First application and validation of the use of a novel measure of heart size (predicted heart mass) to predict post-transplant outcomes.

24. Stehlik J, Feldman DS, Brown RN, VanBakel AB, Russel SD, Ewald GA, et al. Interactions among donor characteristics influence post-transplant survival: a multi-institutional analysis. J Heart Lung Transplant. 2010;29(3):291-8.

25. Smits JM, Vanhaecke J, Haverich A, de Vries E, Smith M, Rutgrink E, et al. Three-year survival rates for all consecutive heart-only and 
lung-only transplants performed in Eurotransplant, 1997-1999. Clin Transpl. 2003:89-100.

26. Razzouk AJ, Johnston JK, Larsen RL, Chinnock RE, Fitts JA, Bailey LL. Effect of oversizing cardiac allografts on survival in pediatric patients with congenital heart disease. J Heart Lung Transplant. 2005;24(2):195-9.

27. Reichart B. Size matching in heart transplantation. J Heart Lung Transplant. 1992;11(4 Pt 2):S199-202.

28. Weiss ES, Allen JG, Patel ND, Russell SD, Baumgartner WA, Shah AS, et al. The impact of donor-recipient sex matching on survival after orthotopic heart transplantation: analysis of 18 000 transplants in the modern era. Circ Heart Fail. 2009;2(5): 401-8. First large-scale UNOS registry analysis to examine the impact of donor:recipient gender matching on survival after heart transplantation.

29. Crandall BG, Renlund DG, O'Connell JB, Burton NA, Jones $\mathrm{KW}$, Gay Jr WA, et al. Increased cardiac allograft rejection in female heart transplant recipients. J Heart Transplant. 1988;7(6):419-23.

30. Prendergast TW, Furukawa S, Beyer 3rd AJ, Browne BJ, Eisen HJ, Jeevanandam V. The role of gender in heart transplantation. Ann Thorac Surg. 1998;65(1):88-94.

31. Erinc K, Yamani MH, Starling RC, Young JB, Crowe T, Ratliff NB, et al. The influence of donor gender on allograft vasculopathy: evidence from intravascular ultrasound. Transplant Proc. 2004;36(10):3129-31.

32. Mehra MR, Stapleton DD, Ventura HO, Escobar A, Cassidy CA, Smart FW, et al. Influence of donor and recipient gender on cardiac allograft vasculopathy. An intravascular ultrasound study. Circulation. 1994;90(5 Pt 2):II78-82.

33. D'Alessandro C, Golmard JL, Barreda E, Laali M, Makris R, Luyt $\mathrm{CE}$, et al. Predictive risk factors for primary graft failure requiring temporary extra-corporeal membrane oxygenation support after cardiac transplantation in adults. Eur J Cardiothorac Surg. 2011;40(4):962-9.

34. Russo MJ, Chen JM, Sorabella RA, Martens TP, Garrido M, Davies $\mathrm{RR}$, et al. The effect of ischemic time on survival after heart transplantation varies by donor age: an analysis of the United Network for Organ Sharing database. J Thorac Cardiovasc Surg. 2007;133(2):554-9.

35. Camarda JA, Saudek D, Otto M, Simpson P, Stendahl G, Berger S, et al. MRI validated echocardiographic technique to measure total cardiac volume: a tool for donor recipient size matching. J Heart Lung Transplant. 2011;30(4):S168.

36. Zuckerman WA, Richmond ME, Singh RK, Chen JM, Addonizio LJ. Use of height and a novel echocardiographic measurement to improve size-matching for pediatric heart transplantation. J Heart Lung Transplant. 2012;31(8):896-902.

37. Bluemke DA, Kronmal RA, Lima JAC, Liu K, Olson J, Burke GL, et al. The relationship of left ventricular mass and geometry to incident cardiovascular events: the MESA (Multi-Ethnic Study of Atherosclerosis) study. J Am Coll Cardiol. 2008;52(25):2148.

38. Kawut SM, Johnson WC, Kronmal RA, Bluemke DA, Lima JAC, Barr RG, et al. Sex and race differences in right ventricular structure and function: the MESA-Right Ventricle study. Circulation. 2011;123(22):2542-51. 